\title{
Metabolic adjustments to moderate maternal nutrient restriction
}

\author{
Natalia E. Schlabritz-Loutsevitch*, Christopher J. Dudley, Jeremiah J. Gomez, C. Heath Nevill, \\ Bonnie K. Smith, Susan L. Jenkins, Thomas J. McDonald, Thad Q. Bartlett, Peter W. Nathanielsz and \\ Mark J. Nijland \\ Center for Pregnancy and Newborn Research, University of Texas Health Science Center Medical School, Department of \\ Obstetrics and Gynecology - MSC 7836, 7703 Floyd Curl Drive, San Antonio, Texas 78229, USA
}

(Received 11 July 2006 - Revised 24 January 2007 - Accepted 31 January 2007)

\begin{abstract}
Reduced food availability in pregnancy influences fetal growth, obstetric outcomes and offspring health in both developing and developed countries. The objective of the present study was to determine responses to moderate global maternal nutrient restriction (MNR) during pregnancy in baboons (Papio hamadryas) - an established non-human primate model for pregnancy-related research. Starting at $30 \mathrm{~d}$ gestation (dG), twelve pregnant baboons received $70 \%$ of food (MNR group) consumed by twenty ad libitum-fed pregnant controls. Maternal body weight, BMI, food intake and physical activity were measured before pregnancy, at $90 \mathrm{dG}$ and at $165 \mathrm{dG}$ (full-term $180 \mathrm{dG}$ ). Fetal and placental weights were recorded at the time of Caesarean section ( 90 and $165 \mathrm{dG}$ ). Activity patterns were also evaluated in fourteen non-pregnant female baboons. Behavioural observations were made in five non-pregnant, six control and four MNR animals. Pregnant baboons decreased overall physical activity and energy-expensive behaviours compared with non-pregnant baboons. In the MNR group, maternal weight, weight gain and maternal physical activity were reduced compared with the control animals. MNR decreased placental weight and volume compared with control, while fetal weight and length were unaffected. We conclude that decreased physical activity and increased usage of maternal available body stores play an important role in the maternal response to pregnancy. Also, adaptations in maternal behaviour and energy utilisation protect fetal growth during moderate MNR.
\end{abstract}

Pregnancy: Baboons: Nutrient restriction: Behaviour: Physical activity

The consequences of excess and shortage in maternal nutrition during pregnancy have been extensively investigated in recent years. Both global maternal nutrient restriction (MNR) and maternal overnutrition have major effects on fetal growth, obstetric outcomes, and offspring health and development, although the effects of global MNR on fetal growth in human pregnancy are controversial. It is often considered that the maternal ability to compensate for decreased availability of nutrients and energy during pregnancy by employing energy-sparing behavioural and metabolic strategies protects fetal growth by matching total maternal energy requirements to energy availability (Poppitt et al. 1993, 1994). Opposing this view, a sharp decline in birth weight has been associated with undernutrition when compared with well-nourished human populations (Stein et al. 2004). The findings regarding the effect of MNR on fetal growth in different animal models are also conflicting most probably due to the nature, degree and timing of restriction (Lumey \& Stein, 1997; Symonds et al. 2004).

Many animal models of MNR have been used during the last 30 years (Schroder, 2003; Armitage et al. 2004): (1) protein restriction $(33-60 \%)$ in rats, pigs and rhesus monkeys; (2) micronutrient restriction in rats; (3) global nutrient restriction $(30-100 \%)$ in rats, sheep and guinea-pigs. Baboons present several advantages for the study of maternal nutrition and fetal growth compared with other non-human primates and non-primate species, including fetal size, which allows the conduct of experimental fetal procedures. Additionally, measurements of fetal body water content, blood constituents, body composition and glycogen stores in this species all closely correlate with values obtained in human fetuses (Brans et al. 1986; Lewis et al. 1989; Pere, 2003). In human pregnancy, intra-uterine growth restriction (IUGR) is defined as fetal weight below the 10th percentile at a given gestational age (American College of Obstetricians and Gynecology, 2000). Because the description of normal growth is critical for diagnosing IUGR, the well-described gross and ultrasonographical values for fetal growth and signs of IUGR in the baboon (Brans et al. 1986; Farine et al. 1988), combined with similarities in placentation, make this species uniquely suited to studying maternal responses to pregnancy-related challenges including MNR.

A very few published studies document energy requirements for wild baboons in their non-pregnant state as well as their adaptation during pregnancy (Hummer, 1970; Muruthi et al. 1991). No such data are available for group-housed captive baboons.

The present study was designed to define the normal pregnancy-related metabolic adaptations (maternal body composition, activity, food consumption and behaviour) of female

\footnotetext{
Abbreviations: dG, days gestation; IUGR, intra-uterine growth restriction; MNR, maternal nutrient restriction.

* Corresponding author: Dr Natalia Schlabritz-Loutsevitch, fax +1 210258 9883, email nschlabritz@icarus.sfbr.org
} 
baboons, and to assess the effect of $30 \%$ MNR (for example, feeding $70 \%$ of food consumed by ad libitum-fed controls) in the second and third trimesters on fetal growth. We hypothesised that maternal adaptation to pregnancy in the baboon would include increased usage of available body stores, increased food intake and decreased physical activity. In addition, we hypothesised that these adaptive mechanisms would be changed by MNR, thereby predisposing the fetus to IUGR.

\section{Materials and methods}

Animal characteristics and experimental design

We present data on fourteen non-pregnant and thirty-two pregnant baboons. All procedures were approved by the Southwest Foundation for Biomedical Research Institutional Animal Care and Use Committee. Baboons were housed in harem groups (one male and fifteen or sixteen females). Animal housing has been described in detail (Schlabritz-Loutsevitch et al. 2004). Briefly, non-pregnant animals underwent physical examination $21-150 \mathrm{~d}$ before introduction of a fertile male into the group. Routine health examination and morphometry were performed on all animals. Baboons were observed twice per $\mathrm{d}$ for injuries and stool abnormalities. The perineum was observed three times per week for signs of perineal turgescence (sex skin swelling) and vaginal bleeding.

Pregnant baboons were randomly assigned to the control or MNR group. Starting at $30 \mathrm{~d}$ gestation (dG) MNR females (n 12) received $70 \%$ of the average daily amount of food eaten (on a body weight-adjusted basis) by control ( $n$ 20) baboons fed ad libitum. Pregnant animals underwent Caesarean sections at $90 \mathrm{dG}$ (eight control; six MNR) and $165 \mathrm{dG}$ (seven control; six MNR) or were allowed to deliver naturally (five control) (Table 1).

\section{Individual feeding, weight recording and food consumption}

Feeding was performed as previously described (SchlabritzLoutsevitch et al. 2004). Once per d animals were run through a chute, over an electronic scale (GSE 665; GSE Scale Systems, Novi, MI, USA) and into individual cages where they had access to food (in the form of Purina Monkey Diet 5038 biscuits) from 07.00 to 09.00 hours or from 11.00 to 13.00 hours. At the end of the $2 \mathrm{~h}$ period animals were returned to the gang cage and the number of biscuits consumed by each animal was recorded. Maternal weight was also recorded within 1-3d after vaginal delivery or Caesarean section.

The total energy cost of gestation was calculated as daily energy expenditure $\times$ length of gestation $\times 1 \cdot 25$, where daily energy expenditure $=93.3 \times$ weight $^{075}$ (weight was calculated as the average weight of the pregnant animal during gestation) as estimated for non-human primates (Portman, 1970; Coehlo, 1986; Key \& Ross, 1999; Aiello \& Key, 2002).

\section{Dual-energy X-ray absorptiometry}

After sedation with ketamine $(10 \mathrm{mg} / \mathrm{kg}$, intramuscular; Ketaset ${ }^{\circledR}$; Fort Dodge Animal Health, Fort Dodge, IA, USA) 
dual-energy X-ray absorptiometry was performed using a GE densitometer (Prodigy $^{\mathrm{TM}}$, GE Lunar Corp., Madison, WI, USA). Body composition was determined by measuring differential attenuation of bone, fat, and lean tissue with minimal radiation exposure. Dual-energy X-ray absorptiometry scans were performed on the trunk and legs (two standard regions) (Bos et al. 2005). The software provided the lean mass, fat mass and bone mineral mass for the total body and for the two standard regions.

\section{Activity registration}

Gross motor activity was measured using an ActiWatch (AW64; MiniMitter Co., Sunriver, OR, USA) (Chen et al. 2003) attached to the underside of the animal's identification tag. This device is an accelerometer that records and summates the amplitude and frequency of motion on a minuteby-minute basis. It was possible for the animals to manually tug at and adjust the tags to which the Actiwatches were attached. The baboons would often do this when agitated or otherwise aroused. The tags were also chewed on and orally manipulated. Though the data that were registered as a result of these behaviours might overstate the amount of activity exhibited, animals that did exhibit those behaviours were, to that extent, more active on average than animals that did not.

\section{Individual behavioural observations}

Video recordings were collected for five non-pregnant control, six pregnant control and four MNR pregnant animals. Video recordings were collected for $10 \mathrm{~d}$ for two $20 \mathrm{~min}$ periods $3 \mathrm{~h}$ apart (early and late afternoon) using the Canon 2000 (Canon USA, Lake Success, NY, USA) and Sony TRV 128 (Sony Corporation, San Diego, CA, USA) video cameras. Pregnant animals were recorded beginning at 91 (SEM 4.3) $\mathrm{dG}$ and ending at 105 (SEM 4.3) dG.

Behavioural analysis was performed using Noldus Observer Video Pro (Noldus Information Technology Inc., Leesburg, VA, USA). An ethogram for behavioural analysis (Coehlo \& Bramblett, 1989) was developed on the basis of the energydependent activities. Energy-taxing behaviours included climbing, running, walking, hanging from the cage, jumping, shaking the cage, threatening, chasing a cagemate, fleeing from or fighting with a cagemate and fighting with an animal in an adjacent cage. Energy-sparing behaviours included standing bipedally or quadrupedally, sitting, presenting genitals to show affiliation or submission, mounting a cagemate, grooming self or a cagemate, or being groomed, manually manipulating the cage or enrichment, and orally manipulating the cage or enrichment.

From the 20 min video recordings, behaviour was continuously sampled from each of the focal animals. The resultant data were analysed by three independent observers who were trained individually until the similarities in their ethogram interpretation reached 85-95\%. Inter-observer reliability was calculated using Noldus Observer Video Pro software (Noldus Information Technology Inc., Leesburg, VA, USA). Total occurrence and percentage of time spent on each particular behaviour were analysed.

\section{Statistical analysis}

In non-pregnant animals, comparisons of the average of $90 \mathrm{~d}$ of activity, weight and food intake between periovulatory, follicular and luteal phases were made using repeated-measures ANOVA and Student-Newman-Keul's test. In the non-pregnant group, daily body weight and BMI were tested for correlation with activity over the $90 \mathrm{~d}$ period of activity recording using Pearson correlations. BMI was calculated, using the length of baboons laid on their backs on a board with a flat surface. Body length (recumbent length) was measured using an anthropometer (catalogue no. N101; SiberHegner Ltd, Zurich, Switzerland) from the crown of the head to the bottom of the right heel with the foot at a right angle to the leg and the knee locked with the leg in full extension. The head was positioned firmly against the fixed board of the anthropometer in the extended position. Length was recorded to the nearest $0 \cdot 1 \mathrm{~cm}$.

In pregnant animals, activity, body weight and energy intake were averaged into $30 \mathrm{~d}$ blocks. Pre-conception activity data were obtained in four baboons in the control pregnant group; this period was compared with $0-30 \mathrm{dG}, 31-60 \mathrm{dG}$ and 61-90 dG data using repeated-measures ANOVA and Dunnett's test. Activity, body weight and energy intake were also compared between control ( $n$ 6) and MNR ( $n$ 3) animals at $60-90 \mathrm{dG}, 91-120 \mathrm{dG}$ and $121-150 \mathrm{dG}$ using two-way repeated-measures ANOVA and Student-Newman-Keul's test. Energy consumption was analysed using two-way ANOVA and Student-Newman-Keul's test to assess differences in treatment and sex. Data throughout are presented as mean values with their standard errors of the mean. Significance was set at $P<0.05$.

\section{Results}

Physical activity, food consumption and body composition before pregnancy

The BMI of fourteen non-pregnant baboons was 17.3 (SEM $0 \cdot 33) \mathrm{kg} / \mathrm{m}^{2}$. Body composition data for eight non-pregnant female baboons are presented in Table 2. Body weight correlated positively with body and trunk lean mass ( $r$ 0.89; $P<0 \cdot 005)$, and BMI correlated positively with trunk lean mass $(r 0.74 ; P<0.05)$.

Measures of gross motor activity were $10.9 \%$ lower during the late luteal and $6.3 \%$ lower during the early follicular phase

Table 2. Body composition of eight non-pregnant female baboons as measured by dual-energy X-ray absorptiometry (Ranges and mean values with their standard errors)

\begin{tabular}{lcrr}
\hline Measurements & Range & Mean & SEM \\
\hline Weight $(\mathrm{kg})$ & $11.4-14.4$ & 13.2 & 0.4 \\
Body length (cm) & $82.6-94$ & 89.1 & 1.4 \\
BMl (kg/m ${ }^{2}$ ) & $15 \cdot 0-18.9$ & 16.7 & 0.6 \\
Body (total) & & & \\
Fat content (\%) & $4-15 \cdot 2$ & 6.6 & 1.4 \\
Fat content $(\mathrm{g})$ & $442-2151$ & 849.9 & 204.8 \\
Lean mass $(\mathrm{kg})$ & $10.1-12.3$ & 11.5 & 0.3 \\
Bone mineral content, total $(\mathrm{g})$ & $474-578$ & 536.4 & 13.6 \\
Bone mineral density, body $\left(\mathrm{g} / \mathrm{cm}^{2}\right)$ & $0.88-0.99$ & 0.9 & 0.01 \\
\hline
\end{tabular}


compared with activity during the periovulatory phase of the menstrual cycle (Fig. 1; $P<0 \cdot 05$ ). Food consumption was higher in the follicular and luteal phases compared with food consumption in the periovulatory phase (13.4 and $14.2 \%$, respectively). Body weight was higher in the periovulatory phase compared with the follicular and luteal phases (Fig. 1; $P<0 \cdot 05$ ).

Average daily physical activity during the $90 \mathrm{~d}$ observation period correlated negatively with BMI $(r-0.726 ; P=0.003)$ and weight $(r-0.687 ; P=0.007)$ and positively with food intake $(r 0.605 ; P=0.022)$ in the fourteen animals studied (Figs. 2 (A), (B) and (C)).

\section{Behavioural observation in non-pregnant animals}

Non-pregnant baboons were inactive $75.9 \%$ of the time. The highest percentage of time spent in an active state was walking (4.7 (SEM 2.11) \%) while the highest percentage of time in an inactive state was sitting $(56.7$ (SEM 15.65) \%) during observations.

\section{Food intake and weight in control and maternal nutrient restriction pregnant baboons}

The total weight gain was lower in MNR ( $v$. control) at $165 \mathrm{dG}$ (Table 3). Daily food intake (per kg weight) and total food intake during pregnancy in the control group did not change with duration of gestation (Table 4, Fig. 3). Maternal weight was higher at the end of gestation compared with the middle of gestation in the control group (Fig. 4). The difference between estimated energy cost of pregnancy and total energy intake was lower in the MNR group ( $v$. control) in the first half of gestation as well as the second half of gestation (Table 5).

\section{Physical activity level and behavioural patterns in pregnant control and maternal nutrient restriction animals}

During the early stages of pregnancy (30-60 and 61-90dG) the level of physical activity in control animals decreased from the pre-pregnancy level (Fig. 3). Physical activity decreased from the middle of gestation to the end of gestation in both control and MNR baboons (Fig. 4). Physical activity was lower in the MNR compared with the control group (Fig. 4). The level of physical activity did not correlate with fetal or placental weight or fetal size at $90 \mathrm{dG}$. No correlation was found between maternal weight and level of physical activity during pregnancy.

Based on the analysis of the behavioural data, pregnant animals were less active than non-pregnant animals. However, this difference was significant only in three cases: hanging from the cage (3.9 (SEM 2.3) \% from total duration of observation in non-pregnant $v \cdot 0 \cdot 1$ (SEM $0 \cdot 0) \%$ in both pregnant groups (control and MNR); $P<0.05$ ), fleeing from a cagemate $(0.2$ (SEM 0.1$) \%$ from total duration of observation in nonpregnant $v \cdot 0 \cdot 0$ (SEM 0.0) \% in both pregnant groups (control and MNR); $P<0.05$ ) and presenting genitals to show affiliation or submission (21.6 (SEM 4.2) as total number of occurrences in non-pregnant, $v .5 \cdot 3$ (SEM 2.5) in control and $8 \cdot 0$ (SEM 1.9) in MNR; $P<0 \cdot 05$ ).

Analysis of control compared with MNR mothers revealed that the only significant difference was a decrease in the average amount of time spent running (1.7 (SEM 0.1) v. 1.1 (SEM $0 \cdot 1) \mathrm{s}$ ), whereas there was no difference in the absolute number of times this behaviour was recorded.

\section{Discussion}

Energy requirements, body composition, activity and behaviour in non-pregnant stage

The energy requirement for a non-pregnant, moderately active women is $167 \mathrm{~kJ}(40 \mathrm{kcal}) / \mathrm{kg}$ per $\mathrm{d}(\mathrm{FAO} / \mathrm{WHO} / \mathrm{UNU}$ Expert Consultation, 1985). The energy consumption of non-pregnant baboons in the present study was 356 (SEM 21) kJ (85 (SEM 5) $\mathrm{kcal}) / \mathrm{kg}$ per d, which is very close to the data published by Stacey (1986) and Nicolosi \& Hunt (1979) for this species, but more than estimated by Leonard \& Robertson (1997) as total daily energy expenditure for a $13 \mathrm{~kg}$ female Papio anubis $(225 \mathrm{~kJ}(53.8 \mathrm{kcal}) / \mathrm{kg}$ per d) and less than the estimation given by Stuedel (2000) for a $11.7 \mathrm{~kg}$ female yellow baboon in the wilderness $(498 \mathrm{~kJ}(119 \mathrm{kcal}) / \mathrm{kg}$ per d). The differences between published data might be due to differences in living conditions. Wild baboons spend 22$75 \%$ of their daytime hours feeding or walking (Altman, 1983; Muruthi et al. 1991), whereas the captive baboons in the present study spent only $3 \%$ of their time in locomotion. A negative correlation of BMI and activity similar to that observed in the present study has also been reported for human subjects (Lawrence \& Whitehead, 1988).
(A)

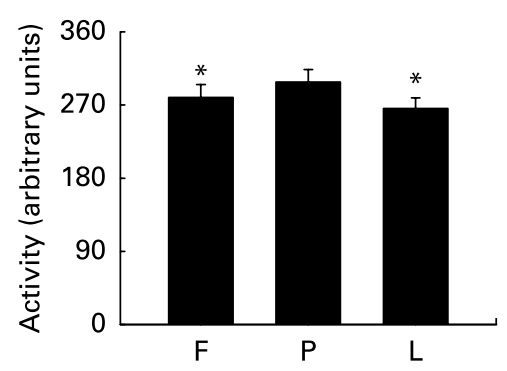

(B)

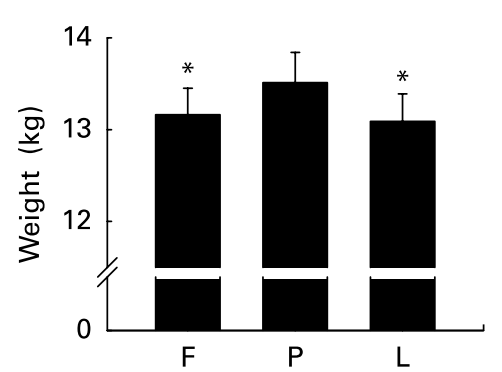

(C)

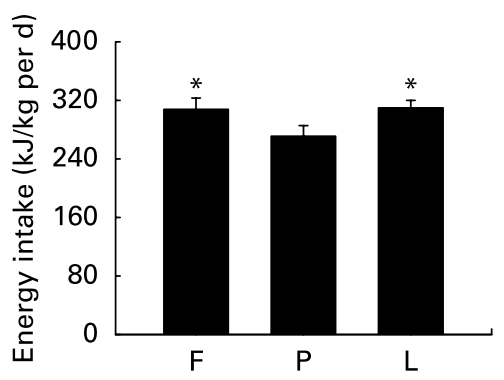

Fig. 1. Activity $(A)$, weight $(B)$ and daily food intake $(C)$ of fourteen non-pregnant baboons during three consecutive menstrual cycles: $F$, follicular phase; $P$, periovulatory phase; L, luteal phase. Data are means, with their standard errors represented by vertical bars. ${ }^{*}$ Mean value was significantly different from that of the periovulatory period $(P<0.05)$. 
(A)

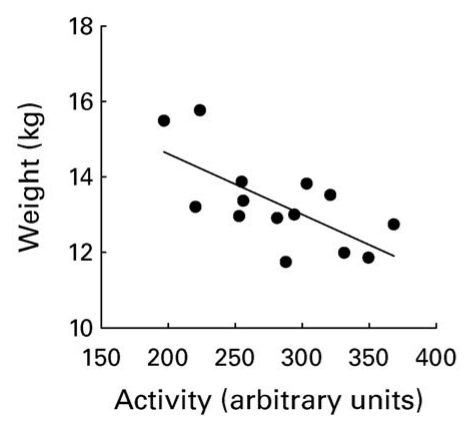

(B)

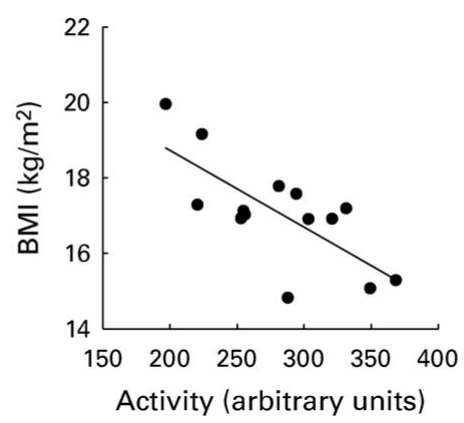

(C)

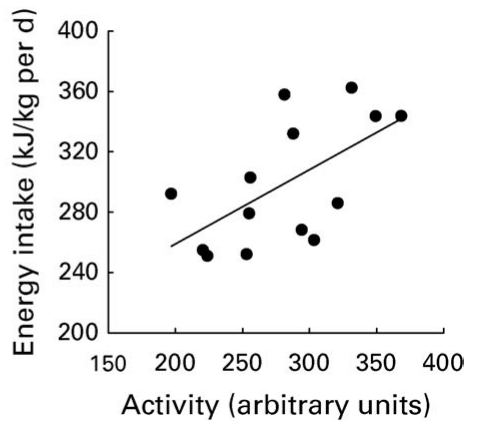

Fig. 2. Relationship of integrated activity and body weight (A) $(r-0.687 ; P=0.007)$, BMI (B) $(r-0.726 ; P=0.003)$ and daily energy intake (C) $(r 0.605 ; P=0.022)$ over a $90 \mathrm{~d}$ period in non-pregnant female baboons $(n 14)$.

Obtaining food is a major source of energy expenditure for baboons in their natural habitat (Rhine \& Westlund, 1978), but not for our captive baboons. Rather, the major factor influencing the activity pattern of captive baboons was the body's hormonal milieu. The decreased level of activity during early follicular and late luteal phases and increased activity during the periovulatory phase is probably a reflection of the hormonal changes during the menstrual cycle and process of metabolic adaptation, as a part of an energy adaptation to conception and implantation (perineal swelling under oestrogen influence in the periovulatory phase is an important reproductive signal) (Keverne, 1987). Menstrual cycle-dependent differences in food consumption in our captive baboons are similar to results published by Bielert \& Busse (1983) for female chacma baboons in captivity.

The total lean body mass and weights in the present study baboons are close to published data in other captive female baboons (Lewis et al. 1986; Mahaney et al. 1993). The percentage of fat-free mass in baboons in the present study $(87 \%)$ was comparable with that calculated for women resident in developing countries (81\%) (Lawrence \& Whitehead, 1988). The present results also accord with another report that female baboons possess a lower fat content than women (Coehlo, 1985).
Leonard \& Robertson (1997) postulated that among primates, species with the higher energy requirements consume more energy-rich diets. The present study extends this observation to include individuals within a species because a high level of physical activity was associated with a higher level of food intake.

\section{Energy requirements, body composition, activity and} behaviour during pregnancy

Activity level decreased during 31-90 dG compared with prepregnancy levels in the control animals. In contrast, another non-human primate species, the ring-tailed lemur in the wild, does not show a difference in activity during early pregnancy (Sauther, 1994). Similar to our observations, a pattern of lower physical activity during pregnancy has been described by Thongprasert et al. (1987) in a study of Thai women, and is assumed in a longitudinal study by Durnin et al. (1985). The reduction of physical activity during pregnancy is a powerful adaptation mechanism to lower energy expenditure and to meet the increased energy costs of pregnancy. In a study of Papio anubis, Leonard \& Robertson (1997) estimated the energy costs for such behavioural activities as hang/bridge to be among the highest energy-required activities (5-fold above

Table 3. Maternal pre-pregnancy weight and maternal, fetal and placental weights during the first and second half of gestation in control baboons and baboons fed $70 \%$ of control (maternal nutrient restriction; MNR)

(Mean values with their standard errors)

\begin{tabular}{|c|c|c|c|c|c|c|c|c|}
\hline & \multicolumn{4}{|c|}{$0-90 \mathrm{dG}$} & \multicolumn{4}{|c|}{$0-165 d G$} \\
\hline & \multicolumn{2}{|c|}{ Control ( $n 8)$} & \multicolumn{2}{|c|}{$\operatorname{MNR}(n 6)$} & \multicolumn{2}{|c|}{ Control $(n 7)$} & \multicolumn{2}{|c|}{$\operatorname{MNR}(n 6)$} \\
\hline & Mean & SEM & Mean & SEM & Mean & SEM & Mean & SEM \\
\hline Pre-pregnant weight (kg) & $13 \cdot 68$ & 0.55 & 13.02 & 0.24 & 15 & 0.89 & 14.93 & 0.43 \\
\hline Caesarian section weight $(\mathrm{kg})$ & $13 \cdot 72$ & 0.44 & $12 \cdot 16^{\star}$ & 0.34 & $16 \cdot 63$ & 0.75 & $14 \cdot 11^{\star}$ & 0.84 \\
\hline Total weight gain $(\mathrm{kg})$ & 0.04 & $0 \cdot 3$ & $-0.86^{*}$ & 0.20 & 1.63 & 0.36 & $-0.82^{*}$ & 0.63 \\
\hline Post-Caesarian section weight $(\mathrm{kg})$ & $12 \cdot 46$ & 0.48 & 11.59 & 0.38 & $14 \cdot 27$ & 0.74 & $13 \cdot 28$ & 0.74 \\
\hline Fetal weight (kg) & 0.1 & 0 & 0.1 & 0 & 0.74 & 0.03 & 0.67 & 0.04 \\
\hline Fetal/maternal weight (\%) & 0.74 & 0.03 & 0.79 & 0.04 & 4.52 & 0.3 & $4 \cdot 78$ & 0.27 \\
\hline Placental weight $(\mathrm{g})$ & $70 \cdot 36$ & 5.45 & 62.93 & 1.48 & $177 \cdot 29$ & 8.52 & $145^{\star}$ & 7.92 \\
\hline Fetal/placental weight (\%) & 1.47 & 0.07 & 1.52 & 0.06 & 4.23 & 0.2 & 4.66 & 0.34 \\
\hline
\end{tabular}

$\mathrm{dG}$, days gestation.

${ }^{*}$ Mean value was significantly different from that of the control animals $(P<0.05)$. 
Table 4. Energy and nutrient intake during the first and second half of pregnancy in the baboon (Mean values with their standard errors)

\begin{tabular}{|c|c|c|c|c|c|c|c|c|c|c|c|c|}
\hline & \multicolumn{4}{|c|}{$0-90 d G$} & \multicolumn{4}{|c|}{$91-165 d G$} & \multicolumn{4}{|c|}{$0-165 d G$} \\
\hline & \multicolumn{2}{|c|}{ Control $(n 20)$} & \multicolumn{2}{|c|}{ MNR ( $n$ 12) } & \multicolumn{2}{|c|}{ Control (n 12) } & \multicolumn{2}{|c|}{$\operatorname{MNR}(n 6)$} & \multicolumn{2}{|c|}{ Control (n 12) } & \multicolumn{2}{|c|}{$\operatorname{MNR}(n 6)$} \\
\hline & Mean & SEM & Mean & SEM & Mean & SEM & Mean & SEM & Mean & SEM & Mean & SEM \\
\hline Intake $(\mathrm{kJ} / \mathrm{d})$ & 4258.5 & $151 \cdot 0$ & $3111 \cdot 2^{*}$ & $103 \cdot 3$ & $4888 \cdot 6$ & $156 \cdot 1$ & $2875 \cdot 7^{*}$ & 159.8 & $4700 \cdot 7$ & $160 \cdot 7$ & $3025 \cdot 0^{*}$ & 171.5 \\
\hline Intake $(\mathrm{kJ} / \mathrm{d}$ per $\mathrm{kg})$ & 308.8 & $13 \cdot 0$ & $230 \cdot 1^{*}$ & 5.4 & 324.3 & 14.6 & $208 \cdot 8^{*}$ & 3.3 & $322 \cdot 2$ & $16 \cdot 1$ & $214 \cdot 6^{\star}$ & 3.8 \\
\hline Protein intake $(\mathrm{g} / \mathrm{d})$ & $39 \cdot 2$ & 1.4 & $28 \cdot 6^{*}$ & 0.9 & 44.9 & 1.4 & $26 \cdot 4^{\star}$ & 1.5 & 43.2 & 1.5 & $27 \cdot 8^{\star}$ & 1.6 \\
\hline Fat intake $(\mathrm{g} / \mathrm{d})$ & $27 \cdot 5$ & 1.0 & $20.1^{*}$ & 0.7 & 31.6 & 1.0 & $18 \cdot 6^{*}$ & 1.0 & 30.4 & 1.0 & $19 \cdot 6^{*}$ & 1.1 \\
\hline Carbohydrate intake $(\mathrm{g} / \mathrm{d})$ & 153.4 & $5 \cdot 4$ & $112 \cdot 0^{*}$ & 3.7 & $175 \cdot 6$ & 5.7 & $103.5^{\star}$ & $5 \cdot 7$ & $169 \cdot 1$ & 5.8 & $108 \cdot 9^{*}$ & $6 \cdot 2$ \\
\hline
\end{tabular}

$\mathrm{dG}$, days gestation; MNR, maternal nutrient restriction.

${ }^{*}$ Mean value was significantly different from that of the control animals $(P<0.05)$.

RMR). Such activity was dramatically decreased in pregnant animals in the present study.

Changes in maternal fat stores during pregnancy in women vary across the world (gain of fat equivalent to $267 \mathrm{MJ}$ in well-nourished women, in contrast to net fat loss of $-23 \mathrm{MJ}$ in undernourished women) (Poppitt et al. 1994; Piers et al. 1995). In the present study, the weight gain during pregnancy in the baboon was 1.63 (SEM 0.63 ) $\mathrm{kg}$, which is $6.93 \%$ of pre-pregnancy weight. Hytten (1980) reported average weight gain during pregnancy in women as $18.8 \%(12.5 \mathrm{~kg})$ of their body weight. Brans et al. (1986) estimated the weight gain during baboon pregnancy as $3.8 \mathrm{~kg}$, which is higher than that we observed. This difference may result from the difference in housing (indoor $v$. outdoor), activity patterns, diet and pre-pregnancy status.

Food consumption by the baboons in the present study was higher compared with calculated energy requirements both before pregnancy and during gestation. Durnin et al.
(A)

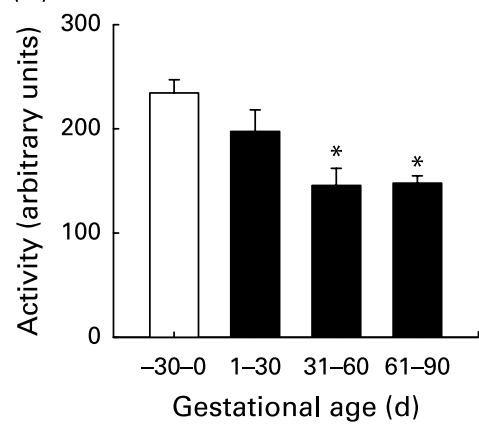

(B)

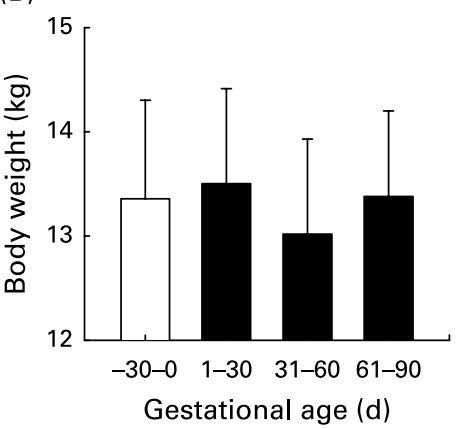

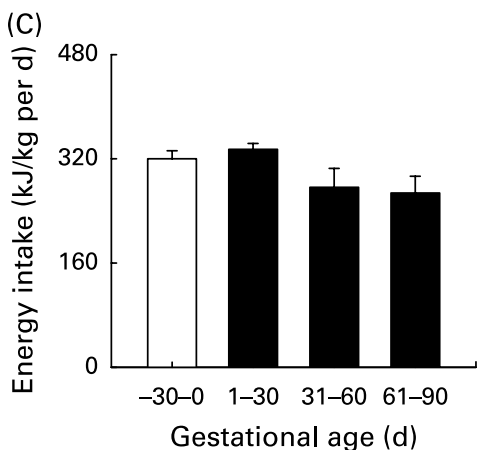

Fig. 3. Activity (A), body weight (B) and daily energy intake (C) in ad libitum-fed (control) baboons $(n$ 4) during $30 \mathrm{~d}$ pre-pregnancy and first 30,60 and $90 \mathrm{~d}$ of pregnancy. Data are means, with their standard errors represented by vertical bars. *Mean value was significantly different from that of the pre-pregnancy period $(-30-0 \mathrm{~d})(P<0.05$; repeated-measures ANOVA and Dunnett's test).

(A)

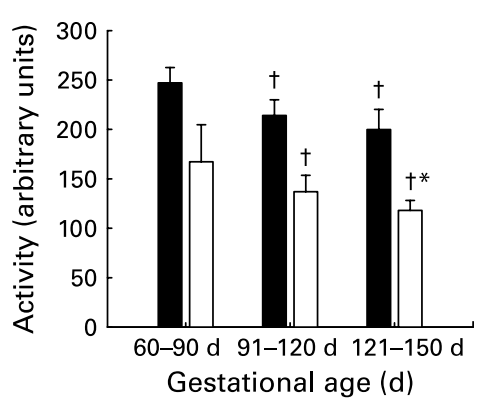

(B)

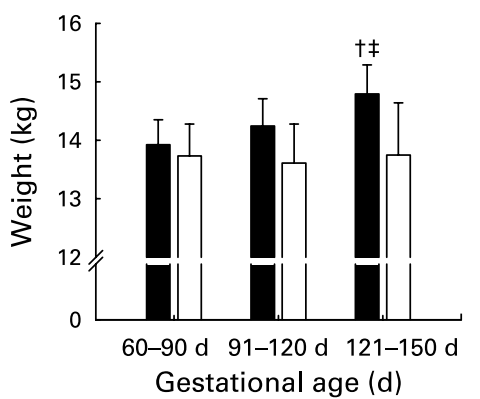

(C)

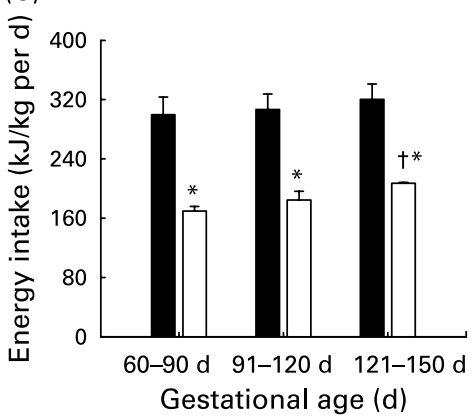

Fig. 4. Activity (A), weight (B) and daily energy intake (C) in ad libitum-fed control $(\mathbf{\square} ; n$ 6) and maternal nutrient restricted ( $\square$; $n$ 3) baboons during three $30 \mathrm{~d}$ periods of pregnancy (60-90 d gestation (dG), 91-120 dG and 121-150 dG). Data are means, with their standard errors represented by vertical bars. ${ }^{*}$ Mean value was significantly different from that of the control group at the same period of gestation $(P<0.05$; repeated-measures ANOVA and Student-NewmanKeul's test). †Mean value was significantly different from that of the same group at $60-90 \mathrm{dG}(P<0.05)$. $¥$ Mean value was significantly different from that of the same group at $91-120 \mathrm{dG}(P<0.05)$. 
(1985) described the opposite in women, for whom the estimated extra energy requirement during pregnancy (335 MJ $(80000 \mathrm{kcal}))$ was higher than actual energy intake $(84 \mathrm{MJ}$ (20000 kcal)). Muruthi et al. (1991) showed that food consumption increased by $57 \%$ in pregnant compared with nonpregnant wild baboons; however, this increase was associated with higher energy expenditure (increasing feeding time). The present results contrast with this observation and the work of Villar et al. (1992), who reported pregnancy-induced hyperphagia in women. On the other hand, pregnant females in the present study did show high levels of oral cage manipulation compared with non-pregnant females, though this difference did not reach the level of significance.

Changes in energy expenditure, body weight, activity and behaviour in pregnant baboons on $30 \%$ maternal nutrient restriction

Nutrition is a part of normal physiological mechanisms that influence reproductive function (Cameron, 1996). Brief interruptions of feeding (missing meals or changing their timing) can suppress reproductive hormone secretion in the rhesus monkey (Macaca mulatta) (Lujan et al. 2006). Dietary changes alter patterns of activity and social behaviour in non-human primates (Bartlett, 2003). In M. mulatta, undernutrition was shown to increase aggression, decrease all behavioural patterns (Loy, 1970), or cause lethargy and apathy (Golub et al. 2000). Decreased overall physical activity observed in our MNR baboons ( $v$. control) supports these results. This decrease of physical activity was associated with unchanged behavioural patterns in MNR compared with control animals and might be the result of decreased small movements (for example, playing with identification tag) that are important regulators of metabolic rate (Levine et al. 1999).

Our finding that the imposed level of MNR was not accompanied by IUGR is consistent with some human studies (Aiello \& Key, 2002), in which the authors reported no differences in fetal:maternal weight ratio in an undernourished human population with a negative energy cost of pregnancy. The present results parallel previous work in sheep undergoing the same degree of restriction during the first half of gestation as used in the present study (30\%) (Osgerby et al. 2002). However, the decreased placental weight and volume at the end of gestation in the present study may reflect a separate adaptive mechanism in which placental growth combined with increased placental efficiency helps to protect fetal growth.

In summary, the present study describes decreased physical activity and usage of available body stores as an adaptation to the energy cost of maintaining pregnancy. We demonstrate that $30 \%$ global MNR decreases physical activity. This energy conservation may help to prevent IUGR. However, the moderate level of MNR to which the mothers were exposed did decrease placental weight at term. We conclude that in the baboon model decreased physical activity and usage of available maternal body stores are major factors regulating metabolic rate and protecting fetal growth.

\section{Acknowledgements}

We are grateful Dr Suzette Tardif for suggestions and critique during manuscript preparation. The present study 
was supported by a grant from the NICHD 21350 and UTHSCSA PREF Award.

\section{References}

Aiello LC \& Key C (2002) Energetic consequences of being a Homo erectus female. Am J Hum Biol 14, 551-556.

Altman J (1983) Costs of reproduction in baboons (Papio cynocephalus). In Behavioral Energetics: The Cost of Survival in Vertebrates, pp. 67-88 [WP Aspey and SL Lustick, editors]. Columbus: Ohio State University.

American College of Obstetricians and Gynecologists (2000) Intrauterine Growth Restriction. ACOG Practice Bulletin no. 12. Washington, DC: ACOG.

Armitage JA, Khan IY, Taylor PD, Nathanielsz PW \& Poston L (2004) Developmental programming of the metabolic syndrome by maternal nutritional imbalance: how strong is the evidence from experimental models in mammals? J Physiol 561, 355-377.

Bartlett TQ (2003) Intragroup and intergroup social interactions in white-handed gibbons. Int J Primatol 24, 239-259.

Bielert C \& Busse C (1983) Influences of ovarian hormones on the food intake and feeding of captive and wild female chacma baboons (Papio ursinus). Physiol Behav 30, 103-111.

Bos G, Snijder MB, Nijpels G, Dekker JM, Stehouwer CD, Bouter LM, Heine RJ \& Jansen H (2005) Opposite contributions of trunk and leg fat mass with plasma lipase activities: the Hoorn study. Obes Res 13, 1817-1823.

Brans YW, Kuehl TJ, Hayashi RH \& Andrew DS (1986) Body water estimates in intrauterine-growth-retarded versus normally grown baboon neonates. Biol Neonate 50, 231-236.

Cameron JL (1996) Regulation of reproductive hormone secretion in primates by short-term changes in nutrition. Rev Reprod $\mathbf{1}$, $117-126$.

Chen KY, Acra SA, Majchrzak K, Donahue CL, Baker L, Clemens L, Sun M \& Buchowski MS (2003) Predicting energy expenditure of physical activity using hip- and wrist-worn accelerometers. Diabetes Technol Ther 5, 1023-1033.

Coehlo AM Jr (1985) Baboon dimorphism: growth in weight, length and adiposity from birth to 8 years of age. In Nonhuman Primate Models for Human Growth and Development, pp. 125-159 [ES Watts, editor]. New York: Alan R. Liss.

Coehlo AM Jr (1986) Time and energy budgets. In Comparative Primate Biology. Behavior, Conservation and Ecology, vol. 2, part A, pp. 141-166 [G Mitchell and J Erwin, editors]. New York: Alan R. Liss.

Coehlo AM Jr \& Bramblett CA (1989) Behavior of the genus Papio: ethogram, taxonomy, methods, and comparative measures. In Perspectives in Primate Biology, vol. 3, pp. 117-140 [PK Seth and S Seth, editors]. New Delhi: Today \& Tomorrow's Printers and Publishers.

Durnin JV, McKillop FM, Grant S \& Fitzgerald G (1985) Is nutritional status endangered by virtually no extra intake during pregnancy? Lancet ii, 823-825.

FAO/WHO/UNU Expert Consultation (1985) Energy and Protein Requirements. World Health Organization Technical Report Series no. 724. Geneva: World Health Organization.

Farine D, MacCarter GD, Timor-Tritch IE, Yeh MN \& Stark RI (1988) Real-time ultrasonic evaluation of the baboon pregnancy: biometric measurements. J Med Primatol 17, 215-221.

Golub MS, Keen CL \& Gershwin ME (2000) Moderate zinc-iron deprivation influences behavior but not growth in adolescent rhesus monkeys. J Nutr 130, S354-S357.

Hummer RL (1970) Observation of the feeding of baboons. In Feeding and Nutrition of Nonhuman Primates, pp. 183-203 [RS Harris, editor]. New York: Academic Press.
Hytten FE (1980) Nutrition. In Clinical Physiology in Obstetrics, part 2: Nutrition and Metabolism, pp. 163-192 [FE Hytten and G Chamberlain, editors]. Oxford: Blackwell Scientific Publications.

Keverne EB (1987) Processing of environmental stimuli and primate reproduction. J Zool 213, 395-408.

Key C \& Ross C (1999) Sex differences in energy expenditure in nonhuman primates. Proc Biol Sci 266, 2479-2485.

Lawrence M \& Whitehead RG (1988) Physical activity and total energy expenditure of child-bearing Gambian village women. Eur J Clin Nutr 42, 145-160.

Leonard WR \& Robertson ML (1997) Comparative primate energetics and hominid evolution. Am J Phys Anthropol 102, $265-281$

Levine JA, Eberhardt NL \& Jensen MD (1999) Role of nonexercise activity thermogenesis in resistance to fat gain in humans. Science 283, 212-214.

Lewis DS, Bertrand HA \& Masoro EJ (1986) Total body water-tolean body mass ratio in baboons (Papio sp.) of varying adiposity. J Appl Physiol 61, 1234-1236.

Lewis DS, Bertrand HA, McMahan CA, McGill HC Jr, Carey KD, Masoro EJ (1989) Influence of preweaning food intake on body composition of young adult baboons. Am J Physiol 257, R1128-1135.

Loy J (1970) Behavioral responses of free-ranging rhesus monkeys to food shortage. Am J Phys Anthropol 33, 263-272.

Lujan ME, Krzemien AA, Reid RL \& Van Vugt DA (2006) Developing a model of nutritional amenorrhea in rhesus monkeys. Endocrinology 147, 483-492.

Lumey LH \& Stein AD (1997) Offspring birth weights after maternal intrauterine undernutrition: a comparison within sibships. Am J Epidemiol 146, 810-819.

Mahaney MC, Leland MM, Williams-Blangero S \& Marinez YN (1993) Cross-sectional growth standards for captive baboons: I. Organ weight by chronological age. J Med Primatol 22, 400-414.

Muruthi P, Altmann J \& Altmann S (1991) Resource base, parity and reproductive condition affect females, feeding time and nutrient intake within and between groups of a baboon population. Oecologica 87, 467-472.

Nicolosi RJ \& Hunt RD (1979) Dietary allowance for nutrients in nonhuman primates. In Primates in Nutritional Research, pp. 11-37 [KC Hayes, editor]. New York: Academic Press.

Osgerby JC, Wathes DC, Howard D \& Gadd TS (2002) The effect of maternal undernutrition on ovine fetal growth. J Endocrinol 173, $131-141$.

Pere MC (2003) Materno-foetal exchanges and utilisation of nutrients by the foetus: comparison between species. Reprod Nutr Dev 43, $1-15$.

Piers LS, Diggavi SN, Thangam S, van Raaij JM, Shetty PS \& Hautvast JG (1995) Changes in energy expenditure, anthropometry, and energy intake during the course of pregnancy and lactation in well-nourished Indian women. Am J Clin Nutr 61, 501-513.

Poppitt SD, Prentice AM, Goldberg GR \& Whitehead RG (1994) Energy-sparing strategies to protect human fetal growth. Am J Obstet Gynecol 171, 118-125.

Poppitt SD, Prentice AM, Jequier E, Schutz Y \& Whitehead RG (1993) Evidence of energy sparing in Gambian women during pregnancy: a longitudinal study using whole-body calorimetry. Am J Clin Nutr 57, 353-364.

Portman OW (1970) Nutritional requirements in non-human primates. In Feeding and Nutrition of Non-human Primates, pp. 87-115 [RS Harris, editor]. New York: Academic Press.

Rhine RJ \& Westlund BJ (1978) The nature of a primary feeding habit in different age-sex classes of yellow baboons (Papio cynocephalus). Folia Primatol (Basel) 30, 64-79.

Sauther M (1994) Wild plant use by pregnant and lactating ringtailed lemurs, with implications for early hominid foraging. In Eating on 
the Wild Side, pp. 240-256 [NL Etkin, editor]. Tucson: University of Arizona Press.

Schlabritz-Loutsevitch NE, Howell K, Rice K, Glover EJ, Nevill CH, Jenkins SL, Bill Cummins L, Frost PA, McDonald TJ \& Nathanielsz PW (2004) Development of a system for individual feeding of baboons maintained in an outdoor group social environment. J Med Primatol 33, 117-126.

Schroder HJ (2003) Models of fetal growth restriction. Eur J Obstet Gynecol Reprod Biol 110, S29-S39.

Stacey PB (1986) Group size and foraging efficiency in yellow baboons. Behav Ecol Sociobiol 18, 175-187.

Stein AD, Zybert PA, van de Bor M \& Lumey LH (2004) Intrauterine famine exposure and body proportions at birth: the Dutch Hunger Winter. Int J Epidemiol 33, 831-836.
Stuedel K (2000) The physiology and energetics of movement: effects on individuals and groups. In On the Move. How and Why Animals Travel in Groups, pp. 9-23 [S Boinski and PA Garber, editors]. Chicago: The University of Chicago Press.

Symonds ME, Pearce S, Bispham J, Gardner DS \& Stephenson $\mathrm{T}$ (2004) Timing of nutrient restriction and programming of fetal adipose tissue development. Proc Nutr Soc 63, 397-403. Thongprasert K, Tanphaichitre V, Valyasevi A, Kittigool J \& Durnin JV (1987) Energy requirements of pregnancy in rural Thailand. Lancet ii, 1010-1012.

Villar J, Cogswell M, Kestler E, Castillo P, Menendez R \& Repke JT (1992) Effect of fat and fat-free mass deposition during pregnancy on birth weight. Am J Obstet Gynecol 167, 1344-1352. 